\title{
Sociologia da educação, reprodução das desigualdades e novas formas de dominação
}

Kimi Tomizaki

\author{
Resumo \\ Jean-Pierre Faguer tem se dedicado à análise dos processos \\ de reprodução e reprodução das desigualdades sociais e já foi \\ professor convidado no Brasil em diferentes ocasiões. Nesta \\ entrevista, o autor, que foi colaborador de Pierre Bourdieu \\ no Centre de Sociologie Européenne, discute sua trajetória \\ como pesquisador, o processo de constituição de seus objetos \\ de pesquisa e alguns resultados de suas investigações, bem \\ como apresenta suas reflexões sobre como a sociologia da \\ educação contribui para o adensamento dos estudos da \\ sociologia do trabalho e da sociologia econômica.
}

\section{Palavras-chave}

Desigualdades - Escola - Habitus - Reprodução social Trabalho. 


\title{
Sociology of education, reproduction of inequalities and new forms of domination
}

Kimi Tomizakil

\begin{abstract}
Jean-Pierre Faguer has dedicated himself to the analysis of reproduction processes and of reproduction of social inequalities and has been a guest professor in Brazil on several occasions. In this interview, the author, who was Pierre Bourdieu's collaborator at Centre de Sociologie Européenne, discusses his career as a researcher, the process of defining his research objects and some results of his investigations. The author also presents reflections on how sociology of education contributes to the consolidation of the studies of labor sociology and economic sociology.
\end{abstract}

\section{Keywords}

Inequalities - School - Habitus - Social reproduction - Work.

I- Universidade de São Paulo, São

Paulo, SP, Brasil.

Contact: kimi@usp.br 


\section{Apresentação}

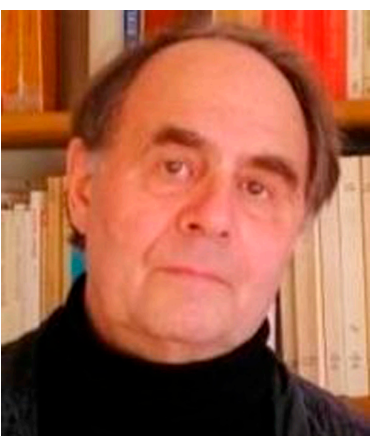

Fonte: Arquivos pessoais do entrevistado.

Jean Pierre Faguer é membro do Centre Européen de Sociologie et de Science Politique da Université Paris-Panthéon-Sorbonne e da École des Hautes Études en Sciences Sociales (EHESS). Foi professor convidado na Faculdade de Educação da Universidade de São Paulo (FEUSP) em 2012, quando ofereceu, em parceria com a Profa. Kimi Tomizaki, a disciplina "Por uma sociologia das rupturas biográficas: intelectuais e militantes de origem popular no campo econômico e intelectual", no quadro do programa de pós-graduação em educação da FEUSP, além de ter participado como conferencista convidado na reunião da Associação Nacional de PósGraduação e Pesquisa em Educação (ANPEd) do mesmo ano. Vale destacar que, antes disso, o autor em questão já havia sido convidado e havia participado de atividades de pesquisa em ensino em diversas universidades brasileiras, tais como o Museu Nacional da Universidade Federal do Rio de Janeiro (UFRJ), a Universidade Estadual de Campinas (Unicamp) e a Pontifícia Universidade Católica do Rio Grande do Sul (PUCRS).

Nascido em 1943, em Paris, Jean-Pierre Faguer tem se dedicado às pesquisas empíricas e reflexões teóricas que colocam em relação as contribuições advindas da sociologia da educação, sociologia do trabalho e sociologia econômica. Graduado em filosofia pela Sorbonne, onde foi orientado por Raymond Aron, Jean-Pierre Faguer se converteu ao campo da sociologia muito cedo, tendo defendido sua tese de Habilitation à diriger des recherches, sob a orientação de Jean-Claude Combessie, quando já trabalhava com Pierre Bourdieu, Christian Baudelot, Alain Chenu e Emmanuèle Raynaud. Como pesquisador no Centre National de la Recherche Scientifique (CNRS), no Centre d'Etudes de l'Emploi (CEE) e no Centre de Sociologie Européenne/École des Hautes Études en Sciences Sociales (CSE/EHESS), desenvolveu diferentes projetos de pesquisa, que redundaram na publicação de vários artigos na revista Actes de la Recherche en Sciences Sociales e outros periódicos de destaque, inclusive no Brasil. Além disso, é autor do livro Khâgneux pour la vie: une histoire des années soixante e coautor de $A$ miséria do mundo, obra coletiva dirigida por Pierre Bourdieu, e desenvolveu atividades de ensino e pesquisa tanto na EHESS quanto na Université Paris 5.

De acordo com o depoimento do autor, ele pertence a uma geração que se formou em um momento em que o ofício de sociólogo não estava ainda profissionalizado: a sociologia dos anos 1960 é marcada pela reconversão de aprendizes de filósofos em direção às ciências sociais, graças à Khâgne (classe preparatória para o ingresso na École Normale Supérieur). Ele conheceu Pierre Bourdieu muito jovem, quando ainda tinha incertezas em relação à sua vocação de sociólogo como profissão, e entrou para o Centre de Sociologie Européenne (CSE) com 23 anos, em setembro de 1966, depois de ter sido beneficiado com uma bolsa de estudos na Unversidade de Tübingen (Alemanha) sob orientação do filósofo Ernst Bloch, ${ }^{1}$ período durante o qual concluiu seus estudos superiores sobre o jovem Lukács.

Assim, entre os trabalhos de campo realizados no $\mathrm{CEE}$, pesquisas que contavam com financiamento estatal abundante e tempo adequado para sua realização, e os trabalhos reflexivos desenvolvidos no CSE e na EHESS, Faguer desenvolveu estudos que poderiam ser classificados em três grandes eixos.

1- Ernst Bloch, (1885 -1977), filósofo marxista, amigo de Lukacs, autor de Thomas Münzer, théologien de la révolution e Le principe espérance. 
0 primeiro deles é o da sociologia da educação, em que Faguer fez pesquisa sobre jovens desempregados sem qualificação em Paris, depois um estudo longitudinal realizado entre 1971 e 1976 sobre uma geração de estudantes de liceus e de ensino técnico que entraram na vida ativa entre 16 e 20 anos, mais precisamente uma pesquisa sobre 6 mil antigos alunos de todos os estabelecimentos escolares (públicos e privados) de quatro departamentos da França (Loir-Atlantique, Ardennes, Hérault e Isère), notadamente na cidade de Grenoble, para conhecer sua situação escolar e profissional quando tinham 16 anos (1972), 18 anos (1974) e 20 anos (1978). O segundo eixo é o da sociologia do trabalho e sociologia econômica, em que o entrevistado fez pesquisas que tinham como objetivo central a análise de biografias para compreender as conexões entre escola, trajetória profissional e vida privada. Em suma, nesse eixo, o pesquisador assumiu como objeto de pesquisa a "entrada na vida ativa" em diálogo com os processos de mobilidade social entre os anos 1968 e 2000, com destaque para três sub-objetos: a precariedade, os trabalhadores de nível técnico e os operários de uma grande empresa (Merlin Gerin) e de uma multinacional da área de informática (Hewlett Packard). E, finalmente, um terceiro eixo, que se desdobra e dialoga diretamente com as pesquisas anteriormente citadas, o da sociologia das formas de reconversão ligadas ao surgimento de novas tecnologias no interior do setor de informática. De acordo com o autor, todos esses trabalhos são essencialmente pesquisas de longa duração realizadas em equipe: inicialmente com Gabrielle Balazs, em Paris, depois em Grenoble, ainda com Gabrielle e também com Michel Gollac e François Bonvin.

De acordo com Jean-Pierre Faguer, a partir do fim da década de 1960, alguns elementos foram fundamentais na concepção, organização e consolidação de suas pesquisas e reflexões em torno dos processos de reprodução social: a aprendizagem do trabalho de sociólogo ao lado de Pierre Bourdieu; o trabalho com a equipe do CSE; os cursos de Bourdieu na EHESS sobre reprodução social, estratégias matrimoniais, grandes escolas e classes preparatórias, para citar alguns temas.

A proposta desta entrevista com JeanPierre Faguer é discutir, por meio da construção dos seus objetos de pesquisa e resultados de investigações, como os principais conceitos cunhados por Pierre Bourdieu, de quem foi colaborador, constituem menos que respostas ou soluções teóricas, mas sobretudo modos de se interrogar os fenômenos sociais, "modos de se construir questões", como Faguer diria, especialmente no que diz respeito aos processos de dominação e reprodução das desigualdades sociais.

No centro desta entrevista, que é a síntese de uma longa discussão, que data de mais de uma década, mas foi organizada nos últimos meses, por ocasião do meu pós-doutoramento em Paris, encontram-se os processos de formação do habitus, que, para Faguer, é o "produto da origem social" (habitus primário), que se expressa em gestos, gostos, categorias de percepção e avaliação do mundo, que é retrabalhada pela escola (habitus secundário), pelo trabalho e por outras experiências ou instâncias educativas, no sentido largo dessa expressão. Diante das recorrentes críticas ao caráter excessivamente determinista da noção de habitus, vale sublinhar que as pesquisas de Faguer contribuem muito para pensar esse conceito em sua potencialidade analítica, visto que nelas o autor concebe um modo de operacionalizar a interrogação sobre como se constituem determinadas posições sociais, no qual as noções de habitus e de campo estão sempre ligadas à ideia de ruptura biográfica e reconversão. Além disso, suas reflexões dão ênfase à expansão do sistema de ensino escolar francês, aos desafios da inserção no mercado de trabalho e ao desenvolvimento de novas e cada vez mais sutis formas de dominação. Nesse sentido, em um contexto social, econômico e político marcado por alterações profundas que, por sua vez, exigem múltiplas adaptações 
por parte dos indivíduos, o habitus pode ser pensado também como um processo de invenção e reinvenção, um princípio gerador de ideias, ações e sentimentos que são novos e, ao mesmo tempo, coerentes em relação aos efeitos dos processos educativos como um todo.

Nesse sentido, nessa entrevista, Faguer discute os efeitos inesperados de um aparelho de reprodução social que rejeita, do mundo do trabalho, não somente indivíduos marginalizados, mas frações inteiras de classes sociais que conseguiram alongar suas trajetórias escolares, por vezes até o ensino superior. Para tais grupos, como desempregados ou trabalhadores precários, não há um lugar e nem tampouco há futuro. E, diante dessa constatação, o autor lança a desafiadora questão de caráter político: como uma sociedade que sacrifica uma parte dela mesma para se reproduzir pode sobreviver e em quais condições ou contradições? E, mais especificamente, como pensar o conjunto das formas de dominação às quais estão sujeitados os trabalhadores precários não qualificados (ou considerados como tal) e os intelectuais precários?

Assim como outros sociólogos próximos de Bourdieu, Faguer esteve sensível às transformações no modo de reprodução social que deslocam as disputas em torno das desigualdades sociais do mundo da escola em direção ao mundo do trabalho: as pesquisas desse autor demonstram que a seleção social se tornou progressivamente mais severa no momento de entrada na vida ativa e depois vai se estender ao longo de toda a vida profissional. Desse ponto de vista, a sociologia da educação torna-se um instrumento essencial para compreender a função social das novas formas de dominação que se apoiam sobre um "habitus econômico" produzido pela escola, como, por exemplo, o estabelecimento de procedimentos de avaliação de determinadas competências relacionados a critérios escolares.

\section{Referências}

BALAZS, Gabrielle; FAGUER, Jean-Pierre. A l'école de l'entreprise, bac d'entreprise et transformation de l'esprit maison. Actes de la Recherche en Sciences Sociales, Paris, n. 69, p. 86-92, 1987.

BALAZS, Gabrielle; FAGUER, Jean-Pierre. Jeunes sans avenir et petit patronat en déclin, Actes de la Recherche en Sciences Sociales, Paris, n. 26-27, p. 49-55, 1979.

BALAZS, Gabrielle; FAGUER, Jean-Pierre. L'évaluation, une nouvelle forme de management, Actes de la Recherche en Sciences Sociales, Paris, n. 114, p. 68-78, 1996. Versão na língua portuguesa: "Uma nova forma de gerenciamento: a avaliação, Veritas, Porto-Alegre, p. 411-426, jun. 1997.

BLOCH, Ernst. Le principe espérance: première, deuxième et troisième parties. t. 1. Trad. de l'allemand par Françoise Wuilmart. Paris: Gallimard, 1976. Título original: Das Prinzip Hoffnung, 1923. (Bibliothèque de philosophie).

BLOCH, Ernst. L'esprit de I'utopie. Paris: Gallimard, 1977. (Bibliothèque de philosophie) Edição de 1923, revista e modificada.

BLOCH, Ernst. Thomas Munzer, théologien de la revolution. Paris: Les Prairies Ordinaires, 2012. Correspondente à edição alemã: Suhrkamp Verlag de 1964. A obra data de 1921.

FAGUER, Jean-Pierre. Khâgneux pour la vie, une histoire des années soixante. Dossiers du Centre d'Études de l'Emploi, n. 5. La Documentation Française, Paris, 1995.

FAGUER, Jean-Pierre. Os khâgneux de 68, objetos e leitores de Os herdeiros. Educação \& Sociedade, Campinas, n. 130, p. 3545, jan./mar, 2015.

FAGUER, Jean-Pierre. Epouse et collaboratrice. In: BOURDIEU, Pierre (Org.). La misère du monde. Paris, Seuil, 1993. p. 809-822. Versão portuguesa: "FAGUER, Jean-Pierre. Esposa e colaboradora In: BOURDIEU, Pierre (Org.). A miséria do mundo. Petrópolis, Vozes, 1997. 


\section{Entrevista}

Como foi o processo de constituição de objetos e problemas de pesquisa ao longo de sua trajetória? E, no mesmo sentido, qual foi a influência de ter trabalhado diretamente com Pierre Bourdieu ou dos conceitos por ele desenvolvidos em sua maneira de pensar o mundo social?

Para me restringir ao essencial: eu pertenço a uma geração de sociólogos que entrou na vida profissional entre o fim da guerra da Argélia (1962) e o Maio de 68. É um período caracterizado, de um lado, por uma conjuntura política marcada pelo fim do colonialismo; e, de outro, por uma conjuntura intelectual fundada sobre a ideologia da escola emancipadora. Entrei no Centre de Sociologie Européenne (CSE/EHESS) em 1966, com uma formação em filosofia. 0 que atraía muitos entre nós no trabalho desenvolvido por Bourdieu era a conexão entre seus trabalhos de etnólogo sobre a Argélia colonial e seus trabalhos como sociólogo do campo intelectual. Dito de outra forma, e sumariamente, éramos atraídos pelo seu projeto de reconciliar a antropologia e a sociologia, o engajamento político e o trabalho de campo.

Pertenço a uma geração que escolheu a sociologia no momento da publicação do livro Os Herdeiros, de Pierre Bourdieu, em 1964. Para compreender a ruptura conceitual que esse livro representou, é preciso situar a obra no contexto intelectual dos anos 1960, o que fiz recentemente no artigo "Os khâgneux de 68, objetos e leitores de "Os herdeiros", publicado no Brasil, na revista Educação \& Sociedade. Bourdieu estava rodeado de colaboradores que tinham, em graus diferentes, sido beneficiados pela meritocracia escolar. Nós tínhamos, majoritariamente, uma trajetória social e universitária próxima daquela realizada por Bourdieu. Como ele, éramos originários das mesmas vias de reprodução das elites intelectuais (liceus burgueses, classes preparatórias para as grandes escolas em alguns liceus prestigiosos do interior da França e de Paris); mas, assim como ele, éramos oriundos do que se costuma denominar, por eufemismo, de um meio social modesto, situação atípica em relação às elites parisienses do mundo estudantil. Tratava-se, portanto, de um grupo de origem popular, provinciana ou estrangeira. A maioria dentre nós era de antigos bolsistas e devia seu status de intelectual à escola republicana, ou seja, nós éramos oblatos, com tudo que essa origem e condição implicam na maneira de trabalhar e se engajar tanto no mundo científico quanto na militância.

No que me diz respeito, pessoalmente, o problema da reprodução social sempre foi o centro de minhas reflexões e das escolhas dos meus objetos de pesquisa. Em particular, o papel da escola como ferramenta para as estratégias de reconversão, materializadas em investimentos nos estudos, em mudanças de emprego, ou ainda em estratégias matrimoniais. Minha análise se apoia principalmente em um trabalho biográfico, que diz respeito a intelectuais ou trabalhadores sem qualificação; meu ponto de vista foi sempre de descrever e compreender a posição e as tomadas de posição dos dominados ou daqueles que são deixados para trás nos processos de reprodução social. $\mathrm{Eu}$ queria estudar, de maneira conjunta, os dois lados dos ofícios propostos aos trabalhadores diplomados de primeira geração. De um lado, estão aqueles que dispõem, no mundo do trabalho, de uma pequena autoridade intelectual ou política: os autodidatas da área de informática, os professores do ensino técnico, os especialistas em divulgação científica, bem como os trabalhadores sociais, os sindicalistas de empresas de alta tecnologia etc. De outro lado, os trabalhadores subalternos da cultura, da arte, das mídias, do cinema etc. Parecia-me que a fronteira entre esses dois mundos era relativamente porosa e que o acesso a um ou ao outro lado dessa fronteira de classe dependia em parte do acaso. Isso é o que eu denomino de acidentes biográficos. 0 que esses profissionais tinham em comum é o fato de terem sido 
beneficiados pela abertura social possibilitada pela escola, sem, no entanto, todos poderem ascender a empregos compatíveis com seu capital cultural ou social.

Suas pesquisas tratam, em diferentes dimensões, de processos de ruptura e, portanto, do habitus como matriz geradora de novos modos de agir no mundo, sem, contudo, deixar de atentar para o fato de que tais rupturas não constituem desconexões. Poderíamos dizer que há uma coerência em termos de trajetória mesmo na ruptura? Você poderia fazer essa discussão a partir de suas pesquisas, que mostram a dimensão inventiva e geradora do habitus em situações de ruptura biográfica, levando em consideração a família, a escola e o trabalho?

Nesse ponto, arriscamo-nos a nos perder em pura especulação e a sermos induzidos ao erro: sabe-se que Bourdieu emprestou o conceito de habitus da história da filosofia. Weber (1987) também empregou esse conceito em sociologia, por exemplo, na Ética protestante e o espírito do capitalismo, para descrever a ética econômica dos puritanos. Do mesmo modo, Durkheim (1938) o empregou em L'Évolution pédagogique en France para descrever o objetivo do trabalho educativo: criar (no aluno) uma disposição geral de espírito e de vontade. 0 que me parece útil aqui é precisar a maneira como o conceito de habitus pode ser utilizado na sociologia da educação nos ajudando a compreender como os modos de aquisição de conhecimentos têm uma dimensão emocional, perceptiva e conceitual. A noção de habitus permite romper com uma visão inocentemente intelectualista dos modos de transmissão do saber, dos modos de aprendizagem tanto do trabalho manual quando do trabalho intelectual. Além disso, essa noção oferece um sistema explicativo das formas de ajustamento ou desajustamento entre os agentes sociais, tanto no mundo do trabalho quanto na vida privada e para a sociologia da família. Desse ponto de vista, como assinala
Bourdieu no livro Noblesse d'État, "a sociologia da educação é um capítulo, e não menos importante, da sociologia do conhecimento e da sociologia do poder" (1969, p. 37).

Para me fazer mais claro, gostaria de evocar a maneira como a noção de habitus, na obra de Bourdieu, é inseparável do que ele chamava de senso do jogo. Durante o Seminário de Paris, cuja intenção era descrever condições concretas do exercício do ofício de sociólogo "dando oportunidade de se conhecer como se passa realmente o trabalho de pesquisa", Bourdieu colocava em relação os processos de aprendizado e as formas de ajustamento das conexões entre os agentes sociais, que nesse ponto guardam proximidade com as análises de Goffman: "O habitus científico é uma regra que constitui o homem, ou melhor, um modus operandi científico funcionando em seu estado prático em conformidade com as normas da ciência, sem ter essas normas em seu princípio. 0 sociólogo que busca transmitir um habitus científico se aproxima mais de um treinador esportivo de alto nível que de um professor da Sorbonne. Ele fala pouco por princípios e preceitos gerais. [...] Ele procede por indicações práticas, muito similares às de um treinador que imita um movimento ('em seu lugar, eu faria assim...'), ou por correções feitas a partir da prática que deve ser cumprida e concebidas no espírito da prática ('eu não colocaria essa questão, pelo menos não dessa forma')" (BOURDIEU; WACQUANT, 1992, tradução nossa). Essa formulação apresenta o benefício de se considerar como inseparáveis atividades mentais e atividades físicas, tanto no caso de um trabalhador manual como no de um intelectual ou mesmo de um artista como Manet (tanto em seu trabalho de copista das obras de Velasquez, que implicava o controle dos gestos e das emoções, como na reprodução de esquemas de pensamento que permitiram a inventividade de seu estilo ulterior; tanto nas suas maneiras de fazer a arte como em sua ética profissional). Trata-se de um exemplo ao qual eu voltarei ao longo da entrevista. 
Assim, pode-se notar que o trabalho não é jamais uma atividade completamente automática. Os ajustamentos entre as tarefas e as formas de cooperação, mesmo no caso do trabalho mais subalterno, apoiam-se em hábitos corporais (posturas, ritmos, momentos de pausa etc.), o que produz um saber incorporado pela imitação e processos de identificação, um processo do qual os corpos carregam os traços (o que Bourdieu chama o corpo memória). Para compreender a força dos modos de dominação no trabalho, é, portanto, necessário levar em consideração as interações contínuas entre trabalho mental e trabalho corporal, que são objeto das aprendizagens tanto escolares como profissionais ou artísticas. Elas têm em comum constituírem produto de interiorização de esquemas de pensamento e de ação incorporados no habitus, organizando as rotinas do comportamento cotidiano no trabalho. Penso igualmente nas descrições de Mauss no seu artigo sobre "as técnicas do corpo" e nas análises, por exemplo, de Karl Bücher (1909) sobre o ritmo de trabalho no mundo do trabalho doméstico e pré-capitalista e sobre sua estreita correspondência com a repetição dos ritmos musicais. ${ }^{2}$ As análises de Bücher haviam interessado profundamente Max Weber no momento em que ele trabalhava com $A$ ética protestante e o espirito do capitalismo.

0 que me parece essencial é que o conceito de habitus permite pensar as rupturas biográficas como rupturas conceituais. 0 habitus, para mim, é um conceito antes de tudo programático. Há conceitos emblemáticos, descritivos, explicativos etc. Eu penso, por exemplo, na crítica de Bourdieu que concerne ao conceito de carisma desenvolvido por Max Weber (conceito que não se localiza muito longe das noções de violência simbólica ou de capital simbólico). No curso sobre Manet, no Collège de France, Bourdieu mostrou a extraordinariedade,

2- BÜCHER, Karl. Arbeit und Rhythmus (Le travail et le rythme). Leipzig, 1909; cf. A apresentação de Max Weber por Isabelle Kalinowski: KALINOWSKI, Isabelle. La science, profession et vocation, suivi de Leçons wébériennes sur la science et la propagande. Agone, Marseilles, 2005. palavra inventada por este, ou o caráter extraordinário do que ele chama revolução simbólica, explicando como o "homem de carisma" é o "homem da descontinuidade": "eu faço a Max Weber, a quem eu muito admiro, uma crítica por ter deixado o carisma como um explicans e não como um explicandum" (BOURDIEU, 2013, p. 379). Dito de outra forma, como um princípio explicativo e não como algo que se trata de explicar. Parece-me que ser capaz de definir o que se trata de explicar é exatamente a tarefa do sociólogo.

Para um pesquisador, de fato, os conceitos devem servir para trabalhar, no sentido que Freud dá ao "trabalho do sonho" na Interpretação dos sonhos, quer dizer, no sentido da economia psíquica, de trabalho mental. É assim que eu concebo o trabalho dos conceitos. E pode-se mostrar como Bourdieu passou progressivamente, dos anos 1960 a 2000, de um conceito programa, formulado no posfácio a Panofsky (1967), de ruptura com a noção idealista de influência intelectual, a um conceito operatório, permitindo compreender, por meio do trabalho monográfico sobre Manet, a inventividade do autor de uma revolução simbólica bem-sucedida. Com o tempo, o conceito perdeu sua rigidez, mesmo com o risco de parecer determinista, para se tornar, ao contrário, um conceito que permite compreender o que torna possíveis as revoluções simbólicas no mundo da arte, das ciências ou da literatura: Manet, Flaubert ou Bauldelaire são exemplos. Essa convicção Bourdieu já tinha em sua cabeça na primeira metade dos anos 1960. Quando ele publica, na Les Temps Modernes (revista dirigida por Sartre), em 1966, o artigo “Campo intelectual e projeto criador", Bourdieu (1966, p. 865) já estava muito consciente que a noção de habitus é um conceito operatório que não tem sentido senão no interior das conexões que ele constitui com as noções de campo e capital cultural. Esse exemplo é uma forma de cuidado contra os usos puramente formais dos conceitos. Os conceitos principais de Bourdieu, como campo, habitus, capital 
(cultural, social, simbólico...) ou modos de dominação (emprestados de Marx), são menos respostas que instrumentos de pesquisa. Dito de outra forma, os grandes conceitos da filosofia e das ciências sociais constituem quadros de pensamento que produzem rupturas com os paradigmas dominantes para se pensar junto os objetos que o pensamento escolástico pensa separadamente. É sobre isso que eu gostaria de insistir nesta entrevista, por meio de exemplos de pesquisas e de maneiras de fazer a pesquisa.

\section{Você poderia falar sobre sua pesquisa a respeito dos khâgneux?}

Eu trabalhei com o habitus dos khâgneux ${ }^{3}$, que é o nome que se dá aos alunos das chamadas classes preparatórias para a École Normale. Podese falar, nesse caso, em um habitus específico em sua dimensão intelectual, emocional e política, típica na França de um modo de formação intelectual laico e republicano, produto da ideologia meritocrática da Terceira República. É um modo de formação que é ligado, como se sabe, à invenção da noção de intelectual (no momento do caso Dreyfus), quer dizer, de um homem público, ao mesmo tempo intelectual e politicamente engajado. É o caso de Durkheim e Bourdieu, entre os sociólogos, e Bergson, Sartre, Merleau-Ponty e Foucault, entre os filósofos. Quer eles tenham ou não se tornado normalianos, são todos produto de um mesmo habitus, que se manifesta na maneira de escrever, pensar, abordar as questões políticas, exprimir suas emoções e controlar seus corpos. Penso, particularmente, em Lévi-Strauss (1981): Tristes Tropiques é um livro que contou muito, para os filósofos da minha geração, como contra-modelo da filosofia acadêmica. Ele contribuiu para a reconversão de bem mais que um filósofo aspirante em direção às ciências sociais.

Embora as khâgnes e a École Normale tenham tido um papel importante na

3- FAGUER, Jean-Pierre. Khâgneux pour la vie, une histoire des années soixante. Dossiers du Centre d'Études de l'Emploi, n. 5. La Documentation Française, Paris, 1995. mobilização estudantil em $1968,{ }^{4}$ fornecendo uma grande parte de seus principais líderes, esse sistema atravessou os anos pós-1968 sem mudanças fundamentais, e isso é um ponto que essa instituição tem em comum com a Igreja. Para dar um exemplo, quando eu entrei em hypokhâgne ${ }^{5}$ no liceu Henri IV, tive, como professor de filosofia, Etienne Borne, que Pierre Bourdieu havia também tido como professor no Lycée Louis-le-Grand doze ou treze anos mais cedo, fato que Bourdieu evoca como um momento importante de sua biografia no livro Les méditations pascaliennes. É verdade que existe uma diferença de geração biológica entre aquela de Pierre Bourdieu, nascida em 1930, e aquela à qual pertence uma grande parte de seus colaboradores que chegam ao CSE ao longo dos anos 1960 e 1970. Mas, do ponto de vista da formação que nós recebemos, pertencemos a uma mesma geração intelectual. Quando comecei a trabalhar no CSE, tinha a impressão de reencontrar a khâgne, sobretudo de fazer uma nova khâgne, mas de outro modo, ou seja, com a intenção de reconverter uma vocação filosófica em capital sociológico.

Pode-se perceber, nesse sentido, que a análise das biografias assume todo seu sentido, na medida em que enfatiza os acidentes biográficos como motores de desclassificação e de reclassificação. E é exatamente nesse ponto que também se destaca a importância determinante do habitus. As rupturas biográficas no mundo do trabalho não atingem somente a vida profissional: elas contribuem igualmente para o questionamento da vida sentimental, da maneira de se situar no mundo social e também têm efeitos sobre as formas de engajamento político. É, por exemplo, o que eu tentei descrever por meio de uma entrevista com uma montadora de filmes, publicada

4- As khâgnes são classes preparatórias, voltadas a alunos de destacado desempenho escolar, que se preparam para os prestigiosos concursos das chamadas grandes escolas, as Écoles Normales Supérieures.

5- 0 primeiro ano do khâgne é uma espécie de "super bac" orientado para a preparação para o concurso para a École Normale. Trata-se de um ano polivalente que precede o momento da escolha entre os estudos de filosofia, história, literatura francesa e línguas antigas e modernas. 
no livro La misère du monde. A história do seu casamento e divórcio com um cineasta é o produto tanto de uma crise sentimental que coloca em questão seu papel como colaboradora do marido ("eu tinha me casado com o projeto de um homem") quanto de uma crise do mundo de trabalho intelectual. Foi o trabalho na sua visão encantada e carismática que os havia aproximado; foi o trabalho que, em sua percepção de violência brutal produzida pela precarização dessa fração profissional, os separou (ver FAGUER , 2003).

Uma outra questão que você abordou em suas pesquisas foram as novas formas de precarização e dominação do trabalho, como no caso acima da "esposa e colaboradora", publicado no livro Miséria do mundo. Você poderia falar um pouco sobre essas questões e também sobre como da exploração no trabalho chegamos ao nível da autoexploração?

Eu tentei compreender o que opunha a cultura e o estilo de vida do mundo operário àqueles do mundo técnico, mais especificamente, o mundo dos assalariados ligados às novas tecnologias, como a informática. Tudo separa esses dois mundos do ponto de vista da disciplina no trabalho, da cultura de classe, do estilo de vida... Em suma, podese falar sobre a transformação de um habitus econômico. De saída, são colocados em curso dois modos de dominação, que correspondem a dois modos de escolarização que se opõem entre si: essencialmente, de um lado, estão as classes populares e, de outro, as classes médias pouco diplomadas em via de ascensão social. Daí a existência de dois mundos de seleção: o mundo do trabalho operário é substituído, pelo fenômeno do alongamento da escolarização, por um mundo caracterizado pela "dominação suave" com fronteiras porosas e, de saída, produtor de incertezas em relação ao futuro, no qual é difícil para cada um saber qual é o seu lugar. Individualismo, concorrência entre assalariados, incerteza em relação ao futuro são fatores de pressão sobre o pessoal nos locais de trabalho. Um sistema de avaliações permanente aproxima as grandes empresas multinacionais do mundo da escola e tende a justificar a seleção dos assalariados e as demissões sob o princípio do mérito: na empresa que estudei, aqueles que são suscetíveis de ser demitidos são os que têm as piores avaliações. Em geral, trata-se de trabalhadores com muitos diplomas, oriundos das classes populares ou de famílias de classes médias ligadas à pequena burguesia econômica (famílias de comerciantes, artesãos ou pequenos empresários). Nessa multinacional de informática situada em Grenoble, o esprit maison tende a misturar constantemente vida privada e vida profissional. Atividades culturais e voluntariado são encorajadas pela direção. A aquisição de um saber autodidata, a prática da bricolagem e o gosto por objetos do universo da informática embaralham a fronteira entre o tempo de trabalho e o tempo de lazer. Essa busca pela polivalência, que está no princípio do recrutamento empresarial ("o potencial”), confundindo constantemente as fronteiras entre o mundo do trabalho e o mundo do não trabalho, tende a implicar um pouco mais os assalariados; dito de outra forma, essas políticas da empresa incitam os trabalhadores a confundir seus interesses pessoais com os interesses da empresa.

0 que é preciso compreender é como as novas formas de dominação no mundo das grandes empresas contribuem para constituir novas formas de autoexploração bem mais eficazes que o sistema do paternalismo operário. Sabe-se que não se controla do mesmo modo os trabalhadores manuais do mundo industrial desde os anos 1950 e também os trabalhadores assalariados subalternos do mundo intelectual ou de grandes empresas de mídias ou de novas tecnologias. As políticas de gestão empresarial das multinacionais se apoiam, antes de tudo, no controle do habitus de seus empregados: o que os empregadores chamam de relacional nas relações de trabalho com os superiores e os colegas têm um papel, de fato, de controle e 
de avaliação das pessoas tão importante quanto a polivalência técnica exigida para ocupar o posto de trabalho. ${ }^{6}$

A cultura informática aproxima, em um mesmo local de trabalho, formas de autoexploração observáveis no campo econômico e no campo de carreiras de enquadramento moral. Em relação à noção de serviço - esse princípio unificador das análises da sociologia do trabalho, da escola e da família -, faz-se necessário sublinhar a ambiguidade desse termo, utilizado tanto pelos economistas (setor de serviços) quanto pelos agentes de enquadramento moral (estar a serviço do povo, da pátria, dos pobres, dos excluídos etc.) no que diz respeito a um dos aspectos mais decisivos do que pode ser chamado, para recuperar a formulação proposta por Pierre Bourdieu (2003, p. 291-295), "a dupla verdade do trabalho”. Se a autoexploração dos pequenos empregadores e pequenos executivos, assim como dos estagiários, vítimas da desvalorização dos diplomas, é frequentemente denunciada como fator de intensificação de exploração econômica, é, de outro lado, a condição primeira de acumulação de um capital que torna possíveis reconversões profissionais. Sendo assim, as técnicas de gestão fundadas na autoexploração constituem formas de dominação ainda mais eficazes: nelas, os empregadores se apoiam em estratégias de acumulação de capital simbólico colocadas em prática pelos desclassificados, os quais visam a manter e, se possível, aumentar um capital pessoal tido como precário pela sua posição no campo econômico.

0 relacional não é redutível, de fato, aos postos do setor de serviços; a importância que os empregadores vinculam hoje às qualidades pessoais para avaliar seus empregados pode

6- A noção de relacional indica o que, em um posto de trabalho, é suscetível de valorizar a pessoa que o ocupa, principalmente em postos de trabalho subalternos, mal pagos e sem qualificação precisa. Trata-se de um modo de lembrar aos empregados subalternos que devem estar sempre a serviço ou à disposição (do chefe, dos colegas, dos clientes etc.) mas também funciona como um poder multiplicador, o qual confere aos postos de trabalho uma dimensão social, ligada à pessoa, sublinhando a importância das maneiras de fazer e das características pessoais: a confiança, as qualidades morais, a apresentação, a educação etc. ser observada em todos os locais de trabalho: não apenas nas fábricas, escritórios, hospitais, supermercados, mas também nos empregos subalternos de atividade intelectual e das mídias. A disponibilidade e a flexibilidade, reforçadas pelo medo de se perder o emprego, suscitam autoavaliação e reconversão permanentes. Porque as relações de trabalho entre colegas, entre empregados e sua hierarquia ou entre os empregados e os clientes tendem a se transformar em relações de força, elas são inseparavelmente relações de dominação nas quais cada posto de trabalho, ao mesmo tempo que implica domínio de uma competência técnica específica, exige certas qualidades ordinariamente exigidas do pessoal do serviço (funcionários da limpeza, do setor de hotelaria etc.). Trata-se, assim, de exemplos de inflação de títulos escolares que transformam empregos sem qualificação em empregos ilusoriamente qualificados.

As competências demandadas tanto dos jovens contratados em empregos precários quanto dos técnicos, executivos e trabalhadores subalternos do setor de empregos culturais respondem à exigência de inspirar confıança, garantia de uma disponibilidade produtiva que deve ser reproduzida no cotidiano. A generalização, no conjunto dos mercados de trabalho, de práticas de recrutamento fundadas na percepção de "sinais de familiaridade" (o que remete à noção de acordo implícito entre determinadas pessoas que se compreendem por meias palavras porque têm o mesmo habitus) com o pessoal contratado (apresentação de si, mas sobretudo um habitus, uma héxis coporal) permite-nos pensar que os modos de dominação econômica se apoiam em lógicas de solidariedade moral entre frações de classe, lógicas essas que contribuem para o reforço de interesses da reprodução social dos grupos mais ameaçados pelo declínio econômico. Foi isso que tentei mostrar por meio do acúmulo das observações de campo, que pude reunir para descrever os modos de enquadramento nas empresas de alta tecnologia e as formas de aprendizagem na prática sobre a informática. 
Essas duas pesquisas centradas no mundo dos autodidatas, mobilizados pela ideia do progresso devido à invenção técnica, ilustram a aplicação pelos iniciantes de estratégias de reclassificação que se tornam possíveis por meio de um trabalho "sobre o posto", relacionando estreitamente a valorização de um saber técnico às características sociais de cada um. As técnicas de recrutamento e de controle dos agentes de enquadramento moral das empresas de alta tecnologia se apoiam, por sua vez, não somente nas redes de apadrinhamento ou de relações familiares, mas, de modo mais geral, considerando, dentre os candidatos anônimos e recrutados em larga escala, em um mercado de escolas nacionais ou mesmo internacionais, os sinais de pertencimento a um universo social e cultural comum e próprio a garantir confiança e cumplicidade. Dito de outra forma, a crise do mundo da reprodução social de frações da pequena burguesa ou da aristocracia operária em declínio contribui para alimentar as modalidades de enquadramento moral do trabalho operário, incluindo os setores produtivos mais modernos.

As condições sociais de acumulação de um capital de autoridade são tão incertas que essa forma de "carisma burocrático", valorizado pelas novas formas de gestão, apoia-se menos no reconhecimento de uma qualificação profissional estável e na garantia advinda de títulos escolares do que num ato de submissão "ao bom cumprimento de uma missão" da empresa, que os executivos devem reconhecer como seus valores pessoais. Sabese que o processo de apagamento e mesmo de anulação de si se apresenta para os oblatos no princípio de sua promoção no interior das instituições, que souberam reconhecer seu mérito. A acumulação de um capital moral (redutível, segundo os campos, ao esprit maison, à vocação, ao voluntariado ou ao militantismo) se apoia na valorização de características muito

7- Sobre a qual Pierre Bourdieu observa "que se adquire distanciando-se da definição burocrática da função", em BOURDIEU, Pierre. Les structures sociales de l'économie. Paris: Seuil, 2001. pessoais das biografias (origem e trajetória social, habitus, hexis corporal) percebidos como sinais de uma submissão potencial à instituição produtora de um reconhecimento das disposições de oblação.

Ainda sobre o habitus e seus efeitos sobre as trajetórias pessoais, profissionais, lembro-me de você falar, no curso na USP e em nossas discussões sobre os indivíduos que, em contextos escolares e de trabalho altamente concorrenciais, mesmo qualificados e diplomados, tornam-se excedentes ou sofrem processos de desclassificação profissional e social. Você poderia falar um pouco sobre essas questões?

Um dos efeitos inesperados da sociologia da educação foi mostrar que a mobilidade social (ascendente ou descendente) pela escola contribuiu para a recomposição do mundo do trabalho. Assim, pode-se observar a aparição de todo um conjunto de novas profissões ligadas ao desajuste entre as estratégias de reconversão e a rigidez do mercado de trabalho. Isso é particularmente visível em universos socialmente muito heterogêneos tanto do ponto de vista do habitus como das competências exigidas, especialmente no mundo dos técnicos, dos neorrurais (desempregados ou trabalhadores urbanos que se instalam em regiões rurais, sobretudo em comunidades, para resistir à desclassificação social), dos artistas e dos criadores de toda sorte na França pós-1968.

Dito de outra forma, a disfunção do habitus (ou seja, um habitus que foi produzido em um dado momento do modo de produção econômico, mas precisa atuar em outro, como no caso de agricultores que se tornam operários) aparece como o produto de falhas nos processos de reprodução social. A passagem de um modo de reprodução familiar na qual a família tinha, salvo acidentes biográficos, o controle da sua reprodução (demográfica, cultural e econômica) a um modo de reprodução delegado à escola transformou o modo de reprodução tradicional 
em um sistema de reprodução social com base estatística. Por base estatística eu quero dizer um modo de seleção baseado na escola, e não numa base individual, que seria o caso quando uma família tem o controle de sua reprodução escolhendo entre seus filhos aquele que será o herdeiro. A base estatística é quando a seleção é produzida pela escola, sobre uma base coletiva, em função do valor atribuído a cada via escolar: técnica/geral; letras/ciências etc. As falhas da reprodução são os efeitos de uma reprodução estatística que tende a sacrificar, ao menos "no papel”, não indivíduos considerados atípicos, mas frações inteiras das classes populares ou médias da geração precedente. "No papel" porque aqueles que são deixados para trás, embora superqualificados em relação aos postos que ocupam, têm todo interesse em resistir à desqualificação, têm interesse, portanto, em se mostrar mais inventivos quanto mais sua posição profissional desqualificada é ambígua e instável.

0 hiato entre suas esperanças e a posição que eles ocupam no mercado de trabalho (das quais é preciso analisar as causas sociais, escolares e profissionais) é o motor de sua inventividade. É nesse sentido que se pode falar de ruptura biográfica, na medida em que a passagem de um modo de reprodução social tradicional, no qual a família tinha um controle quase total sobre sua reprodução, a um modo de reprodução delegado à escola tem por consequência uma superprodução de diplomas. Disso se desdobra a questão: qual será o futuro dos estudantes de um sistema caracterizado por uma nova forma de divisão de trabalho intelectual e na qual a maioria dentre eles serão destinados a tornar-se intelectuais subalternos?

Finalmente, o uso do conceito de habitus permite pensar o conjunto das formas de dominação no trabalho manual e no trabalho intelectual, assim como ampliar a noção marxista de exploração dos operários do mundo industrial às formas de dominação existentes no neoliberalismo, que consome em grande quantidade a força de trabalho dos intelectuais subalternos: precários, profissionais da cultura, especialmente do setor de espetáculos, jornalistas, empregados da mídia, experts de todos os tipos, mas, de fato, mais próximos de trabalhadores independentes que de trabalhadores assalariados. 0 que é impressionante é que eles são, em sua maioria, intelectuais de primeira geração, filhos de operários e de agricultores, comerciantes ou pequenos empresários. Encontramos aqui a análise da insegurança social desenvolvida por Robert Castel, que recoloca a questão do assalariado. 0 que Marx chamava de luta de classes é ainda visível nos nossos dias, mas de uma outra forma, através da luta em torno das classificações inseparavelmente escolares e sociais (a avaliação no trabalho seria um exemplo).

Dito de outra forma, a mobilidade social pela escola inscreve a luta de classes em um quadro de uma história familiar que se desenrola ao longo de várias gerações. Nesse sentido, a sociologia da educação propõe um quadro de análise que permite repensar a sociologia do trabalho e da dominação.

\section{Bibliografia seletiva}

BALAZS, Gabrielle; FAGUER, Jean-Pierre. A l'école de l'entreprise, bac d'entreprise et transformation de l'esprit maison. Actes de la Recherche en Sciences Sociales, Paris, n. 69, p. 86-92, 1987.

BALAZS, Gabrielle; FAGUER, Jean-Pierre. Jeunes sans avenir et petit patronat en déclin, Actes de la Recherche en Sciences Sociales, Paris, n. 26-27, p. 49-55, 1979.

BALAZS, Gabrielle; FAGUER, Jean-Pierre. L'évaluation, une nouvelle forme de management, Actes de la Recherche en Sciences Sociales, Paris, n. 114, p. 68-78, 1996. Versão na língua portuguesa: "Uma nova forma de gerenciamento: a avaliação, Veritas, Porto-Alegre, p. 411-426, jun. 1997. 
BONVIN, François; FAGUER, Jean-Pierre. Une génération d'autodidactes. Actes de la Recherche en Sciences Sociales, Paris, n. 134, p. 78-83, 2000.

BOURDIEU, Pierre. Champ intellectuel et projet créateur. Les Temps Modernes, Paris, n. 246, p. 865-906, nov. 1966.

BOURDIEU, Pierre. La noblesse d’Etat. Paris, Minuit, 1969. p. 37.

BOURDIEU, Pierre. Méditations pascaliennes. Paris: Du Seuil, 2003. p. 291-295.

BOURDIEU, Pierre. Manet, une révolution symbolique. Paris: Éditions Raisons d'agir: Éditions du Seuil, 2013. p. 379.

BOURDIEU, Pierre; WACQUANT, Loïc. La pratique de I'anthropologie réflexive (le séminaire de Paris). In: BOURDIEU, Pierre; WACQUANT, Loïc. Réponses. Paris: Seuil, 1992.

BÜCHER, Karl. Arbeit und Rhythmus (Le travail et le rythme). Leipzig, 1909.

DURKHEIM, Émile. L'évolution pédagogique en France. Paris: PUF, 1938.

FAGUER, Jean-Pierre. Epouse et collaboratrice. In: BOURDIEU, Pierre (Org.). La misère du monde. Paris, Seuil, 1993. p. 809-822. Versão portuguesa: “FAGUER, Jean-Pierre. Esposa e colaboradora In: BOURDIEU, Pierre (Org.). A miséria do mundo. Petrópolis, Vozes, 1997.

FAGUER, Jean-Pierre. Esposa e colaboradora. In: BOURDIEU, Pierre (Org.). A miséria do mundo. Petrópolis: Vozes, 2003.

FAGUER, Jean-Pierre. Le bac "E" et le mythe du technicien. Actes de la Recherche en Sciences Sociales, Paris, n. 50, p. 85-96, 1983.

FAGUER, Jean-Pierre. Le "relationnel" comme pratique et comme croyance. In: KALINOWSKI, Isabelle; RIMBERT, Gérard (Org.). La joie de servir. Paris, Agone, 2007. p.185-203. (Agone: Philosophie, Politique et Sociologie; n. 37).

FAGUER, Jean-Pierre. Les effets d'une éducation totale, un collège jésuite, 1960. Actes de la Recherche en Sciences Sociales, Paris, n. 86-87, p. 25-43, 1991. Versão portuguesa: «FAGUER, Jean-Pierre. Os efeitos de uma educação total: um colégio jesuíta, 1960. Educaçã̃o \& Sociedade, Campinas, n. 58, p. 9-54, 1997.»

FAGUER, Jean-Pierre. 0 trabalho de consagração midiática: a reconversão dos líderes estudantis de maio 68 no campo político e no campo literário, Pro-Posições, n. 14, set./dez., Campinas, Brasil, 2003.

FAGUER, Jean-Pierre. "Os khâgneux de 68, objetos e leitores de Os herdeiros". Educação \& Sociedade, Campinas, n. 130, p. 35-45, jan./mar. 2015.

FAGUER, Jean-Pierre. Révolutionnaires sans révolution. Déclassement et reconversion d'une élite intellectuelle. In: GHEORGHIU, Mihaï Dinu (Org.). Littératures et pouvoir symbolique. Pitesti: Paralela, 2005.

FAGUER, Jean-Pierre. Sociología de campo: profesión y vocación. Revista Espacios en Blanco, Buenos Aires, p. 31-56, mar. 2010.

FAGUER, Jean-Pierre. Stress et évaluation permanente: les effets psychopathologiques des nouvelles formes de management, Journées d'études Iseres-Cgt. In: ISERES-CGT (Org.). Intensité du travail et santé: quelles recherches, quelles actions? Paris: L'Harmattan, 2001.

FAGUER, Jean-Pierre. Une précarité 'classes moyennes'. In: GHEORGHIU, Mihaï Dinu (Org.). La mondialisation des elites. Pitesti: Paralela, 2001.

LÉVI-STRAUSS, Claude. Tristes trópicos. Lisboa: Ed. 70; São Paulo: Martins Fontes, 1981.

LOPES LEITE, J. Sergio; FAGUER, Jean-Pierre. L'invention du style brésilien, sport, journalisme et politique au Brésil. Actes de la Recherche en Sciences Sociales, Paris, n. 103, p. 27-35, 1994.

PANOFSKY, Erwin. Architecture gothique et pensée scolastique. Paris: Le Seuil, 1967. (Le sens commun)

WEBER, Max. A ética protestante e o espírito do capitalismo. 5. ed. São Paulo: Pioneira, 1987. 